\title{
Effect of Dietary Grape Pomace and Seed on Ewe Milk and Meat Quality of Their Suckling Lambs
}

\author{
V. C. Resconi $\mathbb{I D}^{1},{ }^{1}$ M. Pascual-Alonso, ${ }^{1}$ L. Aguayo-Ulloa, ${ }^{1}$ G. C. Miranda-de la Lama, \\ S. Alierta, ${ }^{1}$ M. M. Campo, ${ }^{1}$ J. L. Olleta, ${ }^{1}$ M. Villarroel, ${ }^{3}$ and G. A. María ${ }^{1}$ \\ ${ }^{1}$ Department of Animal Production and Food Science, Faculty of Veterinary, Instituto Agroalimentario de Aragón IA2, \\ Universidad de Zaragoza-CITA, Miguel Servet 177, 50013 Zaragoza, Spain \\ ${ }^{2}$ Group of Animal Welfare and Sustainable Livestock Production, Department of Food Science, \\ Metropolitan Autonomous University (UAM), Lerma Campus, Lerma, MEX, Mexico \\ ${ }^{3}$ Department of Animal Science, E.T.S.I.A. Polytechnic University of Madrid, Madrid, Spain
}

Correspondence should be addressed to V. C. Resconi; resconi@unizar.es

Received 10 December 2017; Revised 2 March 2018; Accepted 22 March 2018; Published 30 April 2018

Academic Editor: Jorge Barros-Velázquez

Copyright (C) 2018 V. C. Resconi et al. This is an open access article distributed under the Creative Commons Attribution License, which permits unrestricted use, distribution, and reproduction in any medium, provided the original work is properly cited.

The effect of wine by-products in the feeding of ewes on fatty acid composition of milk and meat of their suckling lambs and the sensory quality of the meat was investigated. Forty-two ewes were fed during the second half of gestation and lactation one out of three treatments: a control diet based on a commercial concentrate and two concentrates supplemented with either $10 \%$ grape pomace or $5 \%$ grape seed. In addition, all animals had ad libitum access of Lucerne chaff. The control group showed lower concentration of saturated fatty acids (mainly in short and medium chain) and higher monounsaturated fatty acids (mainly oleic acid) in the milk fat, being the total polyunsaturated fatty acids unchanged. However, this variation was not reflected in the meat of the suckling lambs, where only few differences in individual fatty acids were found, such as linoleic acid being highest in the pomace treatment. Spicy and metallic flavours were increased in the wine by-products groups, but overall liking was not affected. The by-products added to the diets may be a good way to reduce costs on feeding and waste, but they were not able to provide a healthier fatty acid profile, neither in milk nor in the meat of the suckling lambs.

\section{Introduction}

Ruminant meat is characterized by high contents of saturated fatty acids (SFA), and since these fatty acids are overconsumed in some countries, they may pose a public health concern [1], although new evidence suggests that excess of carbohydrates instead of fat was associated with higher risk of total mortality in several countries [2]. By animal feeding it is possible to decrease the SFA and promote the enrichment in polyunsaturated fatty acids (PUFA), including $n$-3 PUFA, therefore improving the nutritional value of the meat $[3,4]$. Along these lines, grapes and their derivatives could represent an interesting counterbalance as they have been associated with the prevention of certain diseases, such as cancer [5] and cardiovascular diseases [6], being its benefits associated with the high polyunsaturated fatty acids (PUFA) and phenolic compounds content [7].
It has been established that there is a relationship between dietary fatty acids in animal feed and the fatty acid composition and quality of the meat, including sheep meat [8-12]. Most of the previous studies have compared the quality of meat from lambs fed different diets, such as vegetable oil-supplemented diets [12]. However, in the European Mediterranean region, traditional sheep production systems are devoted to the production of both ewes' milk and meat from suckling lambs reared with their dams on maternal milk only and slaughtered with $30-35$ days $[13,14]$. As suckling lambs behave like monogastrics, the fatty acid composition of maternal milk fat strongly affects the fatty acid composition of their meat [15]. It has been demonstrated that the supplementation of the diets of dairy ruminants with lipid sources can modify the fat composition of their milk $[16,17]$. Therefore, managing ewe diets appears to be a promising strategy for enhancing the quality of suckling lamb meat. 
TABLE 1: Least square means $( \pm$ S.E.) of the weights of ewes fed three types of concentrate and weight and carcass characteristics of their suckling lambs.

\begin{tabular}{lccc}
\hline & Control & Grape pomace (10\%) & Grape seed (5\%) \\
\hline Initial ewes weight $(\mathrm{kg})$ & $44.63( \pm 1.46)$ & $42.75( \pm 1.54)$ & $45.79( \pm 1.41)$ \\
Ewes weight at 15 d lactation $(\mathrm{kg})$ & $50.90( \pm 2.20)$ & $52.02( \pm 2.31)$ & $53.70( \pm 2.11)$ \\
Lambs birth weight $(\mathrm{kg})$ & $3.56( \pm 0.19)$ & $3.68( \pm 0.22)$ & $3.71( \pm 0.20)$ \\
Lambs slaughter weight $(\mathrm{kg})$ & $12.25( \pm 0.61)$ & $11.12( \pm 0.68)$ & $11.76( \pm 0.62)$ \\
Carcass weight $(\mathrm{kg})$ & $5.65( \pm 0.01)$ & $5.63( \pm 0.01)$ & $5.63( \pm 0.01)$ \\
Conformation score & $2.10( \pm 0.24)$ & $1.50( \pm 0.24)$ & $2.09( \pm 0.23)$ \\
Fattening score & $2.10( \pm 0.20)^{\mathrm{a}}$ & $1.70( \pm 0.20)^{\mathrm{ab}}$ & $1.45( \pm 0.19)^{\mathrm{b}}$ \\
\hline
\end{tabular}

${ }^{\mathrm{a}, \mathrm{b}}$ Different letters within raw represent significant difference between treatments $(P<0.05)$.

Some studies have shown that the fatty acid composition of suckling lamb meat can be significantly affected by the feeding regime of the dams [18-20]. Wine by-products, because of their provision of fatty acids (mainly linoleic acid), and as carriers of secondary plant metabolites that could affect ruminal digestion (such as tannins and lignin) or have antioxidant properties (phenolic compounds), could help to obtain a healthier milk and meat [21-24].

In the study of Moñino et al. [25], sheep were fed with pellets containing distilled rosemary leaves and three phenolic compounds were detected in their sucking lambs at higher levels than control diets, which increased the antioxidant capacity of the lamb meat samples. Nevertheless, few studies have dealt with the effect of ewes' diets on other major quality traits of suckling lamb meat, such as sensory characteristics [13].

Thus, we have hypothesized that the inclusion of wine by-products in the ewes diet could transmit a change in the profile of fatty acids of the meat from sucking lambs and in their sensory characteristics.

\section{Materials and Methods}

The study was performed at the Animal Experimentation Service of the University of Zaragoza, Spain (latitude $41^{\circ} 41^{\prime} \mathrm{N}$ ). The area is located in the Ebro Valley, characterized by a dry Mediterranean climate with an average annual temperature of $15^{\circ} \mathrm{C}$ and an average annual rainfall of $317 \mathrm{~mm}$. The study was approved by the Animal Experimentation Ethics Committee of the University of Zaragoza.

2.1. Animals and Diets. A total of 42 Chamarita multiparous adult sheep were used. They were oestrus synchronized with intravaginal progestagen sponges $(30 \mathrm{mg}$ Fluorogestone Acetate; Sincropart ${ }^{\circledR}$, Ceva Salud Animal S.A., Barcelona, Spain) and controlled natural mating was used. Three experimental groups of 14 ewes each were housed during pregnancy and lactation period in pens with a density of $2 \mathrm{~m}^{2}$ per ewe. Each pen was equipped with a metallic water trough $(1.5 \mathrm{~m}$ $\times 0.60 \mathrm{~m})$, metallic feeders $(4.5 \mathrm{~m} \times 0.80 \mathrm{~m}, 27 \mathrm{~cm}$ per ewe), and a lick stone for minerals.

All of the ewes were fed pellet concentrate (11.5 MJ ME/ $\mathrm{kg} \mathrm{DM}$ and $15.5 \%$ crude protein; approximately $0.750 \mathrm{~kg}$ per ewe) and straw ad libitum (5.02 MJ ME/kg DM and 3.5\% crude protein) until the middle of gestation. Then they were allocated in one of three experimental diets, balanced for body weight (see Table 1) and number of lactations (2-3 lactations), as follows:

(1) concentrate without added wine by-products (control);

(2) concentrate supplemented with $10 \%$ of grape pomace, on a dry matter (DM) basis (grape pomace);

(3) concentrate with $5 \%$ of grape seed, on a DM basis (grape seed).

Grape pomace was supplied by a family winery from La Rioja (Spain), whereas grape seeds were obtained from Agralco S. Coop. Ltda. (Estela, Navarra, Spain). The rest of the ingredients of the concentrates were soya (18\%), sunflower oil $(0.5 \%)$, lysine $(0.23 \%)$, methionine $(0.03 \%)$, sodium chloride $(0.4 \%)$, calcium carbonate $(1.12 \%)$, dicalcium phosphate $(0.65 \%)$, vitamin supplement corrector $(0.4 \%)$, and barley (78.67\% for the control treatment, $68.67 \%$ for the grape pomace group, and $73.67 \%$ for the grape seed group). All the ingredients of each concentrate were mixed and ground in a mill and fed as dry meal. The ewes were fed twice a day $(1 \mathrm{~kg} /$ day per ewe), in the morning between 08.00 and $08.30 \mathrm{~h}$ and in the afternoon between 15.00 and $15.30 \mathrm{~h}$, apart from ad libitum access to water and Lucerne (Medicago sativa) chaff (9.07 MJ ME/kg and 20.8\% CP). Concentrate and forage were supplied in separate feeding troughs. Chemical analyses of the grape by-products and the three concentrates and fatty acid composition are shown in Table 2. Since wine by-products were richer in ether extract and fibre, but with less percentage of crude protein with respect to the concentrate control, the corresponding concentrates with the grape pomace and grape seed differed in those components.

After lambing, the newborn lambs were housed with their respective mothers, remaining with them all day, and fed milk by natural suckling throughout the experimental period until slaughter (30 d approximately). Lamb weights and carcass characteristics are shown in Table 1.

2.2. Fatty Acid Composition of Milk. Individual milk samples were collected at the beginning of the milking period in order to assess fatty acid composition. Adapting the methodology described by Lee et al. [26], milk samples were freeze-dried and ground before $0.1 \mathrm{~g}$ dry matter (DM) was weighed into 
TABLE 2: Chemical composition of grape by-products and concentrates used in the diets. Fatty acid composition (g/100 g FAME) of the concentrates.

\begin{tabular}{|c|c|c|c|c|c|}
\hline & \multicolumn{2}{|c|}{ Grape by-products } & \multicolumn{3}{|c|}{ Concentrates } \\
\hline & Pomace & Seed & Control & Grape pomace (10\%) & Grape seed (5\%) \\
\hline Dry matter (DM, \%) & 88.18 & 91.86 & 88.46 & 88.71 & 88.51 \\
\hline Organic matter (OM, \% DM) & 92.14 & 96.11 & 96.41 & 96.62 & 95.81 \\
\hline Ash (\% DM) & 7.86 & 3.89 & 3.59 & 3.38 & 4.19 \\
\hline Ether extract (\%) & 8.94 & 8.89 & 2.51 & 3.49 & 3.83 \\
\hline Crude protein (\%) & 13.26 & 10.87 & 19.28 & 17.09 & 16.96 \\
\hline Neutral detergent fibre (\% DM) & 36.26 & 55.81 & 14.03 & 15.87 & 17.75 \\
\hline Acid detergent fibre (\% DM) & 29.19 & 45.31 & 4.55 & 6.48 & 7.01 \\
\hline Acid detergent lignin (\% DM) & 17.65 & 33.15 & 0.02 & 1.49 & 2.08 \\
\hline Saturated fatty acids & & & 39.80 & 38.47 & 37.70 \\
\hline $\mathrm{C} 14: 0$ & & & 0.29 & 0.25 & 0.24 \\
\hline $\mathrm{C} 16: 0$ & & & 18.10 & 16.10 & 16.10 \\
\hline C18:0 & & & 2.44 & 2.86 & 2.68 \\
\hline C20:0 & & & 0.47 & 0.36 & 0.36 \\
\hline Monounsaturated fatty acids & & & 19.90 & 20.50 & 19.90 \\
\hline $\mathrm{C} 18: 1 n-9$ & & & 18.41 & 18.86 & 18.40 \\
\hline $\mathrm{C} 18: 1 n-11$ & & & 0.99 & 1.09 & 1.11 \\
\hline C20:1 & & & 0.56 & 0.50 & 0.46 \\
\hline Polyunsaturated fatty acids & & & 58.63 & 59.92 & 60.60 \\
\hline $\mathrm{C} 18: 2 n-6$ & & & 54.13 & 56.58 & 56.95 \\
\hline $\mathrm{C} 18: 3 n-3$ & & & 4.50 & 3.30 & 3.60 \\
\hline
\end{tabular}

FAME: total fatty acids methyl ester.

an ultrasound cleaned (USC) culture tube. Then, $2 \mathrm{ml} 0.5 \mathrm{M}$ sodium methoxide in methanol and $1 \mathrm{ml}$ heptane containing

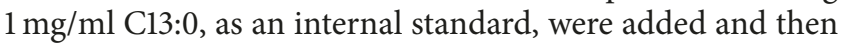
heated for $15 \mathrm{~min}$ at $50^{\circ} \mathrm{C}$. Acetyl chloride in methanol $(1: 10$; $\mathrm{v} / \mathrm{v} ; 2 \mathrm{ml}$ ) was added before mixing thoroughly and heating for $1 \mathrm{~h}$ at $60^{\circ} \mathrm{C}$. Three $\mathrm{ml}$ of heptane, $1 \mathrm{ml}$ of deionised water, and $0.2 \mathrm{~g}$ anhydrous sodium sulphate were added, mixed, and centrifuged at $4^{\circ} \mathrm{C}$ for $5 \mathrm{~min}$ at $1500 \mathrm{rpm}$. The organic solvent top layer was pipetted into a vial to be used for GC analysis.

Fatty acid methyl esters (FAME) were assessed by gas chromatography with a FID detector (Agilent 7820A) using a column $(60 \mathrm{~m} \times 0.25 \mathrm{~mm} \times 0.2 \mu \mathrm{m}$, Agilent HP-88) with split injection, $0.5 \mu \mathrm{l}(40: 1)$, and Helium at a constant flow of $1.5 \mathrm{ml} / \mathrm{min}$ as the carrier gas. Detector temperature was set at $260^{\circ} \mathrm{C}$ and injector oven temperature at $250^{\circ} \mathrm{C}$. The initial temperature of the oven was $125^{\circ} \mathrm{C}$ and then increased by $8^{\circ} \mathrm{C} / \mathrm{min}$ to $145^{\circ} \mathrm{C}$. This was held for $26 \mathrm{~min}$ and then increased by $2^{\circ} \mathrm{C} / \mathrm{min}$ to $220^{\circ} \mathrm{C}$ and held for $5 \mathrm{~min}$. Identification of fatty acids and their response factors was aided with the use of a reference standard (Reference Standard AccuStandard FAMQ-005 + Methyl cis- 7, 10, 13, 16, 19 Docosapentanoate C22:5 Ref 47563-U Supelco + PUFA N ${ }^{\circ} 2$ Animal Source Ref 47015-U Sigma) and quantified using the internal standard (C13:0).

2.3. Meat Samples. A total of 10 lambs from each group were selected to study the meat quality. All of them were slaughtered within the weight range of suckling lamb-type category at an EU-approved abattoir located in the city of
Zaragoza. After overnight lairage, lambs were electrically stunned and slaughtered using standard commercial procedures. After slaughter, the carcasses were stored in cold rooms at $2^{\circ} \mathrm{C}$ for $24 \mathrm{~h}$ and transferred to the Meat Laboratory at the Faculty of Veterinary Medicine of the University of Zaragoza without disrupting the cold chain. The left M. longissimus (thoracis et lumborum) was removed from $\mathrm{T} 1$ to L6 vertebrae. A section from T6 to T10 was vacuum-packed and stored at $-20^{\circ} \mathrm{C}$ to assess fatty acid composition and the section from T13 to L6 was vaccum packed, aged for $72 \mathrm{~h}$ at $4^{\circ} \mathrm{C}$, and then stored at $-20^{\circ} \mathrm{C}$ until the sensory evaluation. Before analyses, the samples were thawed in tap water at $15-17^{\circ} \mathrm{C}$ for $2 \mathrm{~h}$.

2.4. Fatty Acid Composition of Meat. The meat was diced, obtaining two replicates of $150 \mathrm{~g}$, which were freeze-dried and ground before $0.1 \mathrm{~g}$ dry matter (DM) was weighed into an ultrasound cleaned (USC) culture tube. The same methodology as explained in Section 2.2 was followed.

2.5. Sensory Evaluation. Using the Campo et al. [27] technique, sensory analyses were performed in a tasting room with individual booths (ISO 8589:1988). Meat wrapped in aluminium foil was cooked in a double plate grill (SAMMIC P8D-2, Azkoitia, Gipuzkoa, Spain) at $200^{\circ} \mathrm{C}$ until the internal temperature reached $70^{\circ} \mathrm{C}$ monitored by an internal thermocouple (JENWAY 2000, Stone, Staffordshire, UK). During each of the three tasting sessions a trained eight-member sensory panel (ISO 8586-1:1993) evaluated four or two plates containing three samples. External connective tissue and fat 
were trimmed and each sample was cut into eight portions. Each portion was wrapped in aluminium foil, identified, and stored in a warm cabinet at $50^{\circ} \mathrm{C}$ until served to the sensory panel. The time between cooking and serving was $\sim 10 \mathrm{~min}$. To obscure differences in meat colour, samples were served under red light. Each treatment was analysed and compared 10 times for each panel member (80 judgments per treatment). A 10 semistructured points scale was used $(0=$ low, $10=$ high $)$ where panellists scored the degree of lamb odour, lactic odour, tenderness, juiciness, fibrousness, lamb flavour, lactic flavour, metal flavour, fat flavour, spicy flavour, and overall liking. These attributes were developed by panellists using extra samples of the present experiment.

2.6. Data Analysis. Data were analysed using the least squares methods of the GLM procedure using SAS/STAT (9.1 SAS Inst. Inc., Cary, NC, USA) by SAS (1998), fitting a one-way model with a fixed effect of diet (three levels) within the ewes and the lambs data. The general representation of the model used was $y=X b+e$, where $y$ was an $N \times 1$ vector of records, $b$ denoted the fixed effect in the model with the association matrix $X$, and $e$ was the vector of residual effects. Meat and carcass quality variables were covaried with cold carcass weight. A probability of $P<0.05$ values was considered statistically significant.

\section{Results}

In general, we found significant differences $(P<0.05)$ among treatments in the percentage of several individual fatty acids in the milk (mainly SFAs and MUFAs). On the other hand, within the lamb traits, the sensory data and fatty acid profiles of the wine by-products treatments were similar to control, and only few traits showed statistical effects.

3.1. Milk Fatty Acid Composition. The percentage of fatty acid composition of milk fat from ewes fed three types of concentrate is shown in Table 3. Ewe milk from the control group contained a lower proportion $(P<0.05)$, compared to the grape pomace and grape seed groups, of C6:0, C8:0, $\mathrm{C} 10: 0, \mathrm{C} 12: 0$, and $\mathrm{C} 14: 0$. On the contrary, control group presented higher percentages $(P<0.05)$ when compared to the other groups, of C17:0, C16:1, C18:1 n-9, and C18:1 n11. For $\mathrm{C} 16: 0$ and $\mathrm{C} 21: 0$ fatty acids, the milk of the grape pomace treatment had higher percentages $(P<0.05)$ than the rest of the treatments. Regarding stearic acid, control milk had higher percentage $(P<0.05)$ when compared to grape pomace group, but both of them were similar to the grape seed group. Among the polyunsaturated acids, there were differences in $\alpha$-linolenic acid being at higher proportions $(P<0.05)$ in the control group than in the grape seed group, but both of them were similar to the grape pomace group. Overall, there were significant differences in SFA being at lower proportions $(P<0.05)$ in the control group compared to the grape pomace and the grape seed groups and in MUFA, being at higher percentages $(P<0.05)$ in the control group than in the grape pomace and seed groups, but neither in PUFAs, nor in $n-6, n-3, n-6: n-3$, and PUFA : SFA ratios.
3.2. Meat Fatty Acid Composition. The percentage of total fatty acid compositions of the intramuscular fat from suckling lambs reared by ewes fed with the three different types of concentrate is shown in Table 4. Lamb muscle from the grape pomace group contained a significantly lower proportion of C16:0 $(P<0.05)$. Grape seed group presented a percentage of C17:0 significantly lower than the control group $(P<0.05)$, but neither of them was significantly different from the grape pomace group. Among the polyunsaturated acids, there exist significant differences in C18:2 $n-6$, being the percentage higher in the grape pomace group compared to the control group $(P<0.05)$, and both of them similar to the values of the grape seed group. Nevertheless, there were no significant differences in SFA, PUFAs, the PUFA : SFA ratio, or the $n 6$ : $n 3$ ratio between treatments.

3.3. Sensory Evaluation of Meat. The least square means of sensory meat quality variables are presented in Table 5. Two of the 11 sensory attributes were significantly $(P<0.05)$ affected by treatment. Metallic and spicy flavour intensities were higher in the grape seed group compared to the control group and the last one was also higher when compared to the grape pomace group. Overall liking was not affected by treatment.

\section{Discussion}

4.1. Milk Fatty Acid Composition. The fatty acid composition of the concentrate control had the highest proportion of $\alpha$ linolenic acid and the lowest of linoleic acid (Table 2). In the fatty acid composition of the milk, the control group also showed greater percentages of $\alpha$-linolenic acid, being only statistically different from the grape seed group. No further changes in individual, neither global PUFA, were found. Total percentage of PUFA in milk was not affected too much by dietary supplementation with grape pomace in another study with ewes [28] and with grape pomace silage in cows [29], but contradicting our results, these authors did not found also differences in total MUFA and SFA. On the other hand, grape seed inclusion in the diet of dairy sheep can decrease the SFA and increase MUFA and PUFA milk concentration [30], which was thought to be caused by this subproduct being a rich source of linoleic acid and polyphenols, which could modulate the ruminal biohydrogenation of PUFA. The discrepancies with our results are maybe due to the low differences in PUFA between treatments or because our control group may have already a high percentage of unsaturated fatty acids. It has to be taken into account that animals from the three groups were supplemented with Lucerne hay, rich in $n$-3 PUFA.

In our study, the percentages of C18:1 n-9, C16:1, C18:1 n-11 fatty acids and therefore total MUFA in the milk were higher in the control group with respect to the other two groups. Other studies have showed different results, where dried and ensiled grape pomace and grape seeds increased total MUFA, mainly due to the higher concentrations of oleic acids in ruminant milk $[23,30]$, and owed to the higher concentration of fat and linoleic acid in the grape residues. 
TABLE 3: Least square means ( \pm S.E.) of the fatty acid composition ( $g / 100 \mathrm{~g}$ FAME) of milk fat from ewes fed three types of concentrate.

\begin{tabular}{|c|c|c|c|}
\hline Trait & Control & Grape pomace & Grape seed \\
\hline SFA & $59.56 \pm 1.2^{\mathrm{b}}$ & $67.45 \pm 1.2^{\mathrm{a}}$ & $65.31 \pm 1.2^{\mathrm{a}}$ \\
\hline C4:0 & $1.48 \pm 0.05$ & $1.41 \pm 0.05$ & $1.45 \pm 0.05$ \\
\hline C6:0 & $1.35 \pm 0.08^{\mathrm{b}}$ & $1.68 \pm 0.08^{\mathrm{a}}$ & $1.71 \pm 0.08^{\mathrm{a}}$ \\
\hline C8:0 & $1.43 \pm 0.13^{\mathrm{b}}$ & $2.04 \pm 0.13^{\mathrm{a}}$ & $2.02 \pm 0.13^{\mathrm{a}}$ \\
\hline C10:0 & $3.83 \pm 0.5^{\mathrm{b}}$ & $6.59 \pm 0.5^{\mathrm{a}}$ & $6.04 \pm 0.5^{\mathrm{a}}$ \\
\hline C11:0 & $0.06 \pm 0.01$ & $0.08 \pm 0.01$ & $0.08 \pm 0.01$ \\
\hline $\mathrm{C} 12: 0$ & $2.41 \pm 0.3^{\mathrm{b}}$ & $4.15 \pm 0.3^{\mathrm{a}}$ & $3.65 \pm 0.3^{\mathrm{a}}$ \\
\hline C14:0 & $6.1 \pm 0.55^{\mathrm{b}}$ & $9.28 \pm 0.55^{\mathrm{a}}$ & $8.58 \pm 0.55^{\mathrm{a}}$ \\
\hline $\mathrm{C} 15: 0$ & $0.67 \pm 0.05$ & $0.73 \pm 0.05$ & $0.66 \pm 0.05$ \\
\hline $\mathrm{C} 16: 0$ & $23.81 \pm 0.5^{\mathrm{b}}$ & $26.12 \pm 0.5^{\mathrm{a}}$ & $24.65 \pm 0.5^{\mathrm{b}}$ \\
\hline $\mathrm{C} 17: 0$ & $1.49 \pm 0.07^{\mathrm{a}}$ & $1.10 \pm 0.07^{\mathrm{b}}$ & $1.10 \pm 0.07^{\mathrm{b}}$ \\
\hline C18:0 & $16.58 \pm 0.7^{\mathrm{a}}$ & $13.87 \pm 0.7^{\mathrm{b}}$ & $14.98 \pm 0.7^{\mathrm{ab}}$ \\
\hline C20:0 & $0.21 \pm 0.01$ & $0.24 \pm 0.01$ & $0.23 \pm 0.01$ \\
\hline C21:0 & $0.09 \pm 0.006^{\mathrm{b}}$ & $0.10 \pm 0.006^{\mathrm{a}}$ & $0.08 \pm 0.006^{\mathrm{b}}$ \\
\hline MUFA & $36.91 \pm 1.2^{\mathrm{a}}$ & $29.14 \pm 1.2^{\mathrm{b}}$ & $31.07 \pm 1.2^{\mathrm{b}}$ \\
\hline C14:1 & $0.38 \pm 0.03$ & $0.46 \pm 0.03$ & $0.45 \pm 0.03$ \\
\hline C16:1 & $1.46 \pm 0.05^{\mathrm{a}}$ & $1.26 \pm 0.05^{\mathrm{b}}$ & $1.28 \pm 0.05^{\mathrm{b}}$ \\
\hline $\mathrm{C} 18: 1 n-9$ & $33.86 \pm 1.2^{\mathrm{a}}$ & $26.4 \pm 1.2^{\mathrm{b}}$ & $28.28 \pm 1.2^{\mathrm{b}}$ \\
\hline $\mathrm{C} 18: 1 n-11$ & $0.8 \pm 0.03^{\mathrm{a}}$ & $0.6 \pm 0.03^{b}$ & $0.6 \pm 0.03^{\mathrm{b}}$ \\
\hline C20:1 & $0.39 \pm 0.03$ & $0.39 \pm 0.03$ & $0.37 \pm 0.03$ \\
\hline PUFA & $3.44 \pm 0.16$ & $3.32 \pm 0.16$ & $3.54 \pm 0.16$ \\
\hline $\mathrm{C} 18: 2 n-6$ & $2.36 \pm 0.12$ & $2.24 \pm 0.12$ & $2.47 \pm 0.12$ \\
\hline $\mathrm{C} 18: 3 n-6$ & $0.08 \pm 0.01$ & $0.08 \pm 0.01$ & $0.08 \pm 0.01$ \\
\hline $\mathrm{C} 18: 3 n-3$ & $0.38 \pm 0.03^{\mathrm{a}}$ & $0.32 \pm 0.03^{\mathrm{ab}}$ & $0.27 \pm 0.03^{b}$ \\
\hline C20:4 n-6 & $0.37 \pm 0.02$ & $0.4 \pm 0.02$ & $0.44 \pm 0.02$ \\
\hline C20:5 n-3 & $0.07 \pm 0.005$ & $0.08 \pm 0.005$ & $0.07 \pm 0.005$ \\
\hline $\mathrm{C} 22: 5 n-3$ & $0.16 \pm 0.01$ & $0.18 \pm 0.01$ & $0.18 \pm 0.01$ \\
\hline $\mathrm{C} 22: 6 n-3$ & $0.07 \pm 0.01$ & $0.09 \pm 0.01$ & $0.08 \pm 0.01$ \\
\hline n-6 PUFA & $2.82 \pm 0.15$ & $2.83 \pm 0.16$ & $3.00 \pm 0.15$ \\
\hline$n-3$ PUFA & $0.69 \pm 0.05$ & $0.69 \pm 0.05$ & $0.62 \pm 0.05$ \\
\hline PUFA : SFA & $0.060 \pm 0.003$ & $0.054 \pm 0.003$ & $0.055 \pm 0.003$ \\
\hline$n-6: n 3$ & $4.23 \pm 0.30$ & $4.16 \pm 0.32$ & $5.13 \pm 0.30$ \\
\hline
\end{tabular}

$\overline{a, b}$ Different letters within raw represent significant difference between treatments $(P<0.05)$. FAME: total fatty acids methyl ester; SFA: saturated fatty acids; MUFA: monounsaturated fatty acids; PUFA: polyunsaturated fatty acids.

Considering the individual SFA in milk, we have found higher concentrations of even fatty acids from 6 to 14 carbons in the wine by-products groups, whereas only grape pomace differed from the control in the C16:0 and C18:0 fatty acids, being higher and lower, respectively, in the pomace group (Table 1). Since fatty acids C4:0 to C12:0 are almost exclusively arising from de novo synthesis in the mammary gland [16], this process seems to be increased in the ewes fed supplemented wine by-products maybe due to the high percentage of digestible fibre in the concentrate which could favour the acetate to propionate ratio and therefore the synthesis of short and medium chain fatty acids [31]. However, grape residues also provide higher levels of nonfermentable fibre, lignin, which could affect the ruminal digestibility resulting in a decreased percentage of de novo fatty acids in the milk, as found by Moate et al. [23] and Manso et al. [24], using diets containing grape pomace and ensiled grape pomace.
Contradicting our results, Correddu et al. found lower milk fat concentration of these fatty acids, which was attributed to the increase source of PUFA when grape seed was included in the diet of ewes [30], since long-chain fatty acids available in plasma from diet (or from fat mobilisation) decrease medium chain fatty acids (C8:0 to C14:0) percentages in the milk, both by a dilution effect and by a reduction in their synthesis [16]. The higher concentration of PUFA in the wine by-products in the concentrates of the present study might be minimal to observe this effect and, by the other hand, hay provided could have an influence.

4.2. Meat Fatty Acid Composition. The fatty acid composition of meat has been related to human health [1] which accounts for the interest in finding ways to produce healthier meat (higher ratio of PUFA to SFA and a more favourable balance 
TABLE 4: Least square means ( \pm S.E.) of fatty acid (g/100 g FAME) of intramuscular fat from suckling lambs reared by ewes fed three types of concentrate.

\begin{tabular}{|c|c|c|c|}
\hline Trait & Control & Grape pomace & Grape seed \\
\hline SFA & $48.69 \pm 0.8$ & $47.75 \pm 0.8$ & $49.7 \pm 0.8$ \\
\hline C10:0 & $0.32 \pm 0.02$ & $0.34 \pm 0.02$ & $0.36 \pm 0.02$ \\
\hline $\mathrm{C} 12: 0$ & $0.85 \pm 0.06$ & $0.78 \pm 0.06$ & $0.9 \pm 0.06$ \\
\hline C14:0 & $6.75 \pm 0.24$ & $6.29 \pm 0.24$ & $6.73 \pm 0.24$ \\
\hline $\mathrm{C} 15: 0$ & $0.53 \pm 0.02$ & $0.51 \pm 0.02$ & $0.52 \pm 0.02$ \\
\hline C16:0 & $25.4 \pm 0.42^{\mathrm{a}}$ & $24.2 \pm 0.42^{\mathrm{b}}$ & $25.45 \pm 0.42^{\mathrm{a}}$ \\
\hline $\mathrm{C} 17: 0$ & $1.13 \pm 0.03^{\mathrm{a}}$ & $1.07 \pm 0.03^{\mathrm{ab}}$ & $1.03 \pm 0.03^{b}$ \\
\hline C18:0 & $13.54 \pm 0.3$ & $14.37 \pm 0.3$ & $14.52 \pm 0.3$ \\
\hline C20:0 & $0.14 \pm 0.01$ & $0.16 \pm 0.01$ & $0.16 \pm 0.01$ \\
\hline MUFA & $39.89 \pm 0.8$ & $39.44 \pm 0.8$ & $37.82 \pm 0.8$ \\
\hline C14:1 & $0.44 \pm 0.01$ & $0.40 \pm 0.01$ & $0.42 \pm 0.01$ \\
\hline C16:1 & $2.35 \pm 0.08$ & $2.14 \pm 0.08$ & $2.17 \pm 0.08$ \\
\hline $\mathrm{C} 18: 1 n-9$ & $35.88 \pm 0.8$ & $35.64 \pm 0.8$ & $34.02 \pm 0.8$ \\
\hline C18:1 n-11 & $1.20 \pm 0.04$ & $1.24 \pm 0.04$ & $1.20 \pm 0.04$ \\
\hline PUFA & $11.4 \pm 0.7$ & $12.8 \pm 0.7$ & $12.4 \pm 0.7$ \\
\hline $\mathrm{C} 18: 2 n-6$ & $5.29 \pm 0.27^{\mathrm{b}}$ & $6.15 \pm 0.27^{\mathrm{a}}$ & $5.94 \pm 0.27^{\mathrm{ab}}$ \\
\hline $\mathrm{C} 18: 3 n-6$ & $0.09 \pm 0.01$ & $0.12 \pm 0.01$ & $0.12 \pm 0.01$ \\
\hline $\mathrm{C} 18: 3 n-3$ & $0.53 \pm 0.03$ & $0.61 \pm 0.03$ & $0.55 \pm 0.03$ \\
\hline $\mathrm{C} 20: 3 n-6$ & $0.25 \pm 0.03$ & $0.27 \pm 0.03$ & $0.29 \pm 0.03$ \\
\hline C20:4 n-6 & $3.66 \pm 0.3$ & $3.89 \pm 0.3$ & $3.92 \pm 0.3$ \\
\hline $\mathrm{C} 20: 5 n-3$ & $0.41 \pm 0.04$ & $0.46 \pm 0.04$ & $0.43 \pm 0.04$ \\
\hline $\mathrm{C} 22: 5 n-3$ & $0.76 \pm 0.06$ & $0.82 \pm 0.06$ & $0.79 \pm 0.06$ \\
\hline $\mathrm{C} 22: 6 n-3$ & $0.39 \pm 0.04$ & $0.44 \pm 0.04$ & $0.4 \pm 0.04$ \\
\hline n-6 PUFA & $9.3 \pm 0.6$ & $10.4 \pm 0.6$ & $10.3 \pm 0.6$ \\
\hline$n$-3 PUFA & $2.1 \pm 0.16$ & $2.34 \pm 0.16$ & $2.19 \pm 0.16$ \\
\hline PUFA : SFA & $0.234 \pm 0.02$ & $0.265 \pm 0.02$ & $0.251 \pm 0.02$ \\
\hline$n-6: n 3$ & $4.53 \pm 0.24$ & $4.52 \pm 0.24$ & $4.75 \pm 0.24$ \\
\hline
\end{tabular}

${ }_{\mathrm{a}, \mathrm{b}}$ Different letters within raw represent significant difference between treatments $(P<0.05)$. FAME: total fatty acids methyl ester; SFA: saturated fatty acids; MUFA: monounsaturated fatty acids; PUFA: polyunsaturated fatty acids.

TABLE 5: Least square means $( \pm$ S.E.) of sensorial meat quality variables in suckling lambs reared by ewes fed three types of concentrate.

\begin{tabular}{lccr}
\hline Response variable & Control & Grape pomace & Grape seed \\
\hline Lamb odour intensity & $5.62 \pm 0.22$ & $5.97 \pm 0.22$ & $5.77 \pm 0.22$ \\
Milk odour intensity & $1.88 \pm 0.15$ & $1.84 \pm 0.15$ & $1.71 \pm 0.15$ \\
Lamb flavour intensity & $6.19 \pm 0.19$ & $6.22 \pm 0.19$ & $6.06 \pm 0.19$ \\
Milk flavour intensity & $2.54 \pm 0.2$ & $2.13 \pm 0.2$ & $2.17 \pm 0.2$ \\
Metallic flavour intensity & $3.5 \pm 0.16^{\mathrm{b}}$ & $3.77 \pm 0.16^{\mathrm{ab}}$ & $4.11 \pm 0.16^{\mathrm{a}}$ \\
Fat flavour intensity & $4.35 \pm 0.26$ & $4.17 \pm 0.26$ & $4.48 \pm 0.26$ \\
Spicy flavour intensity & $2.75 \pm 0.14^{\mathrm{b}}$ & $2.88 \pm 0.14^{\mathrm{b}}$ & $3.25 \pm 0.14^{\mathrm{a}}$ \\
Tenderness & $6.14 \pm 0.38$ & $6.24 \pm 0.38$ & $6.22 \pm 0.38$ \\
Juiciness & $5.79 \pm 0.19$ & $5.68 \pm 0.19$ & $5.75 \pm 0.19$ \\
Fibrousness & $4.31 \pm 0.34$ & $4.44 \pm 0.34$ & $4.37 \pm 0.34$ \\
Overall liking & $5.15 \pm 0.22$ & $5.02 \pm 0.22$ & $5.11 \pm 0.22$ \\
\hline
\end{tabular}

a,b Different letters within raw represent significant difference between treatments $(P<0.05)$.

between $n-6$ and n-3 PUFA) [8, 9]. Previous works have related the fatty acid profile of sheep milk to the meat from suckling lambs [20]. However, in our study, we did not find significant differences in the fatty acid profile of meat between treatments related to that found in milk from the dams. Probably, the lack of differences between groups of lambs may be due to individual variation within groups. Moreover, the differences found in C16:0 and C17:0, being the percentage of the two saturated fatty acids greater in control lambs and the C18:2 n-6 lower, could be related to the higher fatness score of the control lambs (Table 1), since the amount of fat has an effect on meat FA composition, independent 
of the diet $[32,33]$. The content of SFA and MUFA increases faster than PUFA as fatness increases, leading to a reduction in the relative proportion of PUFA [9], but this increment was not enough in our study to show significant differences between groups in total SFA, MUFA, and PUFA. Thus, although diet seemed to vary fatness scores, the differences were not enough to affect the intramuscular lipid values or PUFA : SFA ratio to total PUFAs or the $n-6: n-3$ ratio between treatments.

In this study, we found differences in the percentage of $\alpha$-linolenic acid, which seems surprising taking into account the lack of differences in this fatty acid in the milk fat of the lactating ewes. In a previous study, suckling lambs, whose mother's diets were supplemented with $5 \%$ or $10 \%$ of grape pomace, had greater proportion of vaccenic, rumenic acids, and $n-3: n-6$ ratio, but a lower oleic acid percentage in their intramuscular fat compared to a control diet [34]. This effect was thought to be related to the contribution of linoleic acid and the inhibitory effect of some phenolic compounds present in the wine by-product on ruminal biohydrogenation [24,35]. However, a fourth treatment used in the same study, with $500 \mathrm{mg} \mathrm{kg}^{-1}$ of $\alpha$-tocopherol added, showed similar results than the grape pomace treatments (with no contribution of further fatty acids and phenolic compounds) [34]. In another study, grape pomace and grape seeds supplemented directly to lambs did not affect the fatty acid profile of the meat [36].

4.3. Sensory Evaluation of Meat. The sensory attributes defined by panellists were two odours (lamb and milk), five flavours (lamb, milk, metal, grass, and hot), and three texture characteristics (tenderness, juiciness, and fibrousness). In our study, the use of grape pomace and grape seed added to the ration of lactating ewes affected spicy and metallic flavour intensities, being those higher in lamb meat from the grape seed group, but neither other sensory parameters nor overall liking was affected. Phenolic compounds are important odorants in lamb meat and have been described as spicy in a gas chromatography olfactometry [37], so they might contribute to the spicy flavour found in the sensory analysis of the present study. The aromatic phenolic compounds in the meat of ruminants can come directly from those present in feeds or as a product of the microbial fermentation of lignin, between other reactions in the rumen or when cooking [38]. Moñino et al. [25] showed that by-products rich in phenolic compounds to sheep feeding allowed the transfer of these compounds to the meat of their suckling lambs, so it could be possible that phenolic compounds present in the grape seed were transferred to the milk and the lamb meat, affecting their flavour. Other way to form this volatile could be through the microbial fermentation of lignin, highly present in the grape seed treatment.

\section{Conclusions}

The addition of $10 \%$ grape pomace and $5 \%$ grape seed to the concentrate of lactating ewes practically did not affect the fatty acid profile of suckling lambs meat, although there were changes, mostly in the saturated and monounsaturated fatty acid percentages of the fat milk. The sensory evaluation of meat showed differences in spicy and metallic flavours, but they did not affect overall liking of the different types of products. Different doses, presentations of the product, time on feed, and so forth are necessary to explore. Furthermore, the overall feed ingredients and composition need to be considered since contradicting results were found in the bibliography with respect to the use of these by-products and their effect in fatty acid composition in ruminant milk and meat.

\section{Conflicts of Interest}

The authors declare that there are no conflicts of interest regarding the publication of this article.

\section{Acknowledgments}

This study was funded by the Spanish Ministry of Science (Project AGL-2008-02088/GAN). Many thanks are due to the Autonomous Community of La Rioja for the Scholarship Ph.D. Program (Programa de Ayudas Predoctorales del Gobierno de la Rioja) of M. Pascual-Alonso. V. C. Resconi was supported by the Juan de la Cierva-Incorporación Program (MINECO, Spain). Thanks are also due to the staff of the Animal Research Centre of the University of Zaragoza (SEA). Special thanks are due to Inmaculada Álvarez for the advice, support, and help in the fatty acid profiles analysis.

\section{References}

[1] K. D. Cashman and A. Hayes, "Red meat's role in addressing 'nutrients of public health concern"' Meat Science, vol. 132, pp. 196-203, 2017.

[2] M. Dehghan, A. Mente, X. Zhang et al., "Associations of fats and carbohydrate intake with cardiovascular disease and mortality in 18 countries from five continents (PURE): a prospective cohort study," The Lancet, vol. 390, no. 10107, pp. 2050-2062, 2017.

[3] L. A. Sinclair, "Paper presented at the 9th annual Langford Food Industry Conference, Bristol, 24-25 May 2006 - Nutritional manipulation of the fatty acid composition of sheep meat: A review," Journal of Agricultural Science, vol. 145, no. 5, pp. 419434, 2007.

[4] E. Jerónimo, C. M. M. Alfaia, S. P. Alves et al., "Effect of dietary grape seed extract and Cistus ladanifer L. in combination with vegetable oil supplementation on lamb meat quality," Meat Science, vol. 92, no. 4, pp. 841-847, 2012.

[5] V. Nandakumar, T. Singh, and S. K. Katiyar, "Multi-targeted prevention and therapy of cancer by proanthocyanidins," Cancer Letters, vol. 269, no. 2, pp. 378-387, 2008.

[6] E. N. Frankel, A. L. Waterhouse, and P. L. Teissedre, "Principal phenolic phytochemicals in selected California wines and their antioxidant activity in inhibiting oxidation of human lowdensity lipoproteins," Journal of Agricultural and Food Chemistry, vol. 43, no. 4, pp. 890-894, 1995.

[7] C. Yi, J. Shi, J. Kramer et al., "Fatty acid composition and phenolic antioxidants of winemaking pomace powder," Food Chemistry, vol. 114, no. 2, pp. 570-576, 2009. 
[8] J. D. Wood, R. I. Richardson, G. R. Nute et al., "Effects of fatty acids on meat quality: a review," Meat Science, vol. 66, no. 1, pp. 21-32, 2004.

[9] K. Raes, S. de Smet, and D. Demeyer, "Effect of dietary fatty acids on incorporation of long chain polyunsaturated fatty acids and conjugated linoleic acid in lamb, beef and pork meat: a review," Animal Feed Science and Technology, vol. 113, no. 1-4, pp. 199-221, 2004.

[10] J. S. Elmore, S. L. Cooper, M. Enser et al., "Dietary manipulation of fatty acid composition in lamb meat and its effect on the volatile aroma compounds of grilled lamb," Meat Science, vol. 69, no. 2, pp. 233-242, 2005.

[11] E. Dransfield, “The taste of fat," Meat Science, vol. 80, no. 1, pp. 37-42, 2008.

[12] T. Manso, R. Bodas, T. Castro, V. Jimeno, and A. R. Mantecon, "Animal performance and fatty acid composition of lambs fed with different vegetable oils," Meat Science, vol. 83, no. 3, pp. 511516, 2009.

[13] C. Vieira, A. Fernández-Diez, J. Mateo, R. Bodas, S. Soto, and T. Manso, "Effects of addition of different vegetable oils to lactating dairy ewes' diet on meat quality characteristics of suckling lambs reared on the ewes' milk," Meat Science, vol. 91, no. 3, pp. 277-283, 2012.

[14] C. Sañudo, A. Sanchez, and M. Alfonso, "Small ruminant production systems and factors affecting lamb meat quality," Meat Science, vol. 49, no. 1, pp. S29-S64, 1998.

[15] M. A. Lane, R. L. Baldwin VI, and B. W. Jesse, "Sheep rumen metabolic development in response to age and dietary treatments," Journal of Animal Science, vol. 78, no. 7, pp. 19901996, 2000.

[16] Y. Chilliard, A. Ferlay, R. M. Mansbridge, and M. Doreau, "Ruminant milk fat plasticity: Nutritional control of saturated, polyunsaturated, trans and conjugated fatty acids," Animal Research, vol. 49, no. 3, pp. 181-205, 2000.

[17] P. Schmidely and D. Sauvant, "Taux butyreux et composition de la matière grasse du lait chez les petits ruminants : Effets de l'apport de matières grasses ou d'aliment concentré," Productions Animales, vol. 14, no. 5, pp. 337-354, 2001.

[18] M. A. Valvo, M. Lanza, M. Bella et al., "Effect of ewe feeding system (grass v. concentrate) on intramuscular fatty acids of lambs raised exclusively on maternal milk," Journal of Animal Science, vol. 81, no. 3, pp. 431-436, 2005.

[19] M. A. Lurueña-Martínez, C. Palacios, A. M. Vivar-Quintana, and I. Revilla, "Effect of the addition of calcium soap to ewes' diet on fatty acid composition of ewe milk and subcutaneous fat of suckling lambs reared on ewe milk," Meat Science, vol. 84, no. 4, pp. 677-683, 2010.

[20] T. Manso, R. Bodas, C. Vieira, A. R. Mantecón, and T. Castro, "Feeding vegetable oils to lactating ewes modifies the fatty acid profile of suckling lambs," Animal, vol. 5, no. 10, pp. 1659-1667, 2011.

[21] E. Tsiplakou and G. Zervas, "Comparative study between sheep and goats on rumenic acid and vaccenic acid in milk fat under the same dietary treatments," Livestock Science, vol. 119, no. 1-3, pp. 87-94, 2008.

[22] V. Vasta and G. Luciano, "The effects of dietary consumption of plants secondary compounds on small ruminants' products quality," Small Ruminant Research, vol. 101, no. 1-3, pp. 150-159, 2011.

[23] P. J. Moate, S. R. O. Williams, V. A. Torok et al., "Grape marc reduces methane emissions when fed to dairy cows," Journal of Dairy Science, vol. 97, no. 8, pp. 5073-5087, 2014.
[24] T. Manso, B. Gallardo, and C. Guerra-Rivas, "Modifying milk and meat fat quality through feed changes," Small Ruminant Research, vol. 142, pp. 31-37, 2016.

[25] I. Moñino, C. Martínez, J. A. Sotomayor, A. Lafuente, and M. J. Jordán, "Polyphenols transmission to Segureño lamb meat from ewes' diet supplemented with the distillate from rosemary (Rosmarinus officinalis) leaves," Journal of Agricultural and Food Chemistry, vol. 56, no. 9, pp. 3363-3367, 2008.

[26] M. R. F. Lee, J. K. S. Tweed, E. J. Kim, and N. D. Scollan, "Beef, chicken and lamb fatty acid analysis - a simplified direct bimethylation procedure using freeze-dried material," Meat Science, vol. 92, no. 4, pp. 863-866, 2012.

[27] M. M. Campo, C. Sañudo, B. Panea, P. Alberti, and P. Santolaria, "Breed type and ageing time effects on sensory characteristics of beef strip loin steaks," Meat Science, vol. 51, no. 4, pp. 383-390, 1999.

[28] T. Manso, B. Gallardo, A. Salvá et al., "Influence of dietary grape pomace combined with linseed oil on fatty acid profile and milk composition," Journal of Dairy Science, vol. 99, no. 2, pp. 1111$1120,2016$.

[29] N. W. Santos, G. T. D. Santos, D. C. Silva-Kazama et al., "Production, composition and antioxidants in milk of dairy cows fed diets containing soybean oil and grape residue silage," Livestock Science, vol. 159, no. 1, pp. 37-45, 2014.

[30] F. Correddu, G. Gaspa, G. Pulina, and A. Nudda, "Grape seed and linseed, alone and in combination, enhance unsaturated fatty acids in the milk of Sarda dairy sheep," Journal of Dairy Science, vol. 99, no. 3, pp. 1725-1735, 2016.

[31] G. Pulina, A. Nudda, G. Battacone, and A. Cannas, "Effects of nutrition on the contents of fat, protein, somatic cells, aromatic compounds, and undesirable substances in sheep milk," Animal Feed Science and Technology, vol. 131, no. 3-4, pp. 255-291, 2006.

[32] K. Nürnberg, J. Wegner, and K. Ender, "Factors influencing fat composition in muscle and adipose tissue of farm animals," Livestock Production Science, vol. 56, no. 2, pp. 145-156, 1998.

[33] J. Santos-Silva, I. A. Mendes, and R. J. B. Bessa, "The effect of genotype, feeding system and slaughter weight on the quality of light lambs 1. growth, carcass composition and meat quality," Livestock Production Science, vol. 76, no. 1-2, pp. 17-25, 2002.

[34] C. Guerra-Rivas, B. Gallardo, L. Paz et al., "Los niveles de ácido ruménico y ácido vacénico de la grasa intramuscular de los lechazos aumentan al incorporar orujo de uva en la ración de las ovejas," in AIDA, XVI Jornadas sobre Producción Animal, Zaragoza, Spain, 2015.

[35] C. Guerra-Rivas, B. Gallardo, Á. R. Mantecón, M. del ÁlamoSanza, and T. Manso, "Evaluation of grape pomace from red wine by-product as feed for sheep," Journal of the Science of Food and Agriculture, vol. 97, no. 6, pp. 1885-1893, 2017.

[36] C. Guerra-Rivas, C. Vieira, B. Rubio, and T. Manso, "Grape pomace and grape seed extract in lambs diet: meat fatty acid profile andantioxidant activity," in Proceedings of the 64th Annual Meeting of the European Federation of Animal Science (EAAP), Wageningen Academic Publishers, 2013.

[37] M. Bueno, V. C. Resconi, M. M. Campo, J. Cacho, V. Ferreira, and A. Escudero, "Gas chromatographic-olfactometric characterisation of headspace and mouthspace key aroma compounds in fresh and frozen lamb meat," Food Chemistry, vol. 129, no. 4, pp. 1909-1918, 2011.

[38] V. C. Resconi, A. Escudero, and M. M. Campo, "The development of aromas in ruminant meat," Molecules, vol. 18, no. 6, pp. 6748-6781, 2013. 


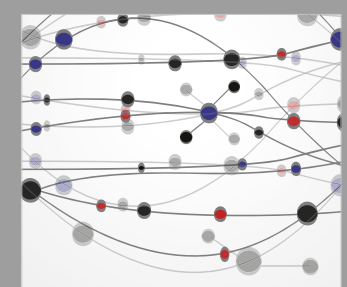

The Scientific World Journal
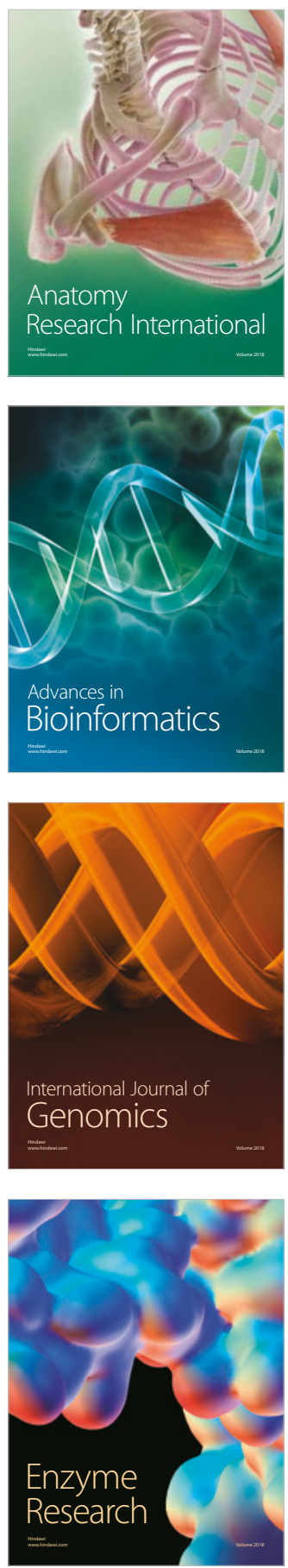
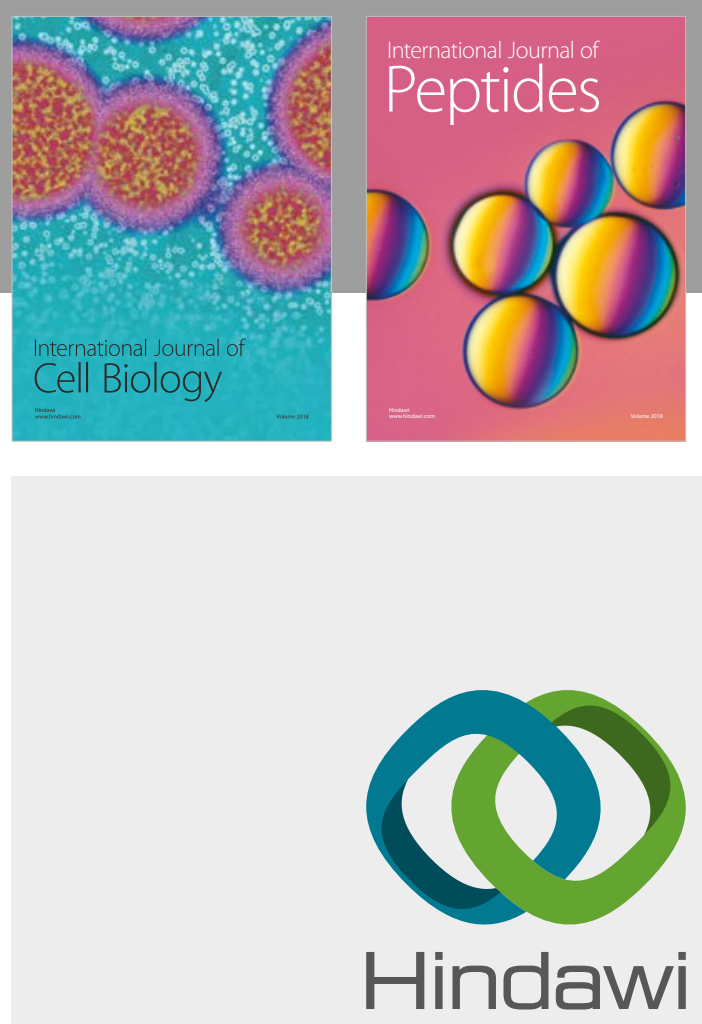

Submit your manuscripts at

www.hindawi.com
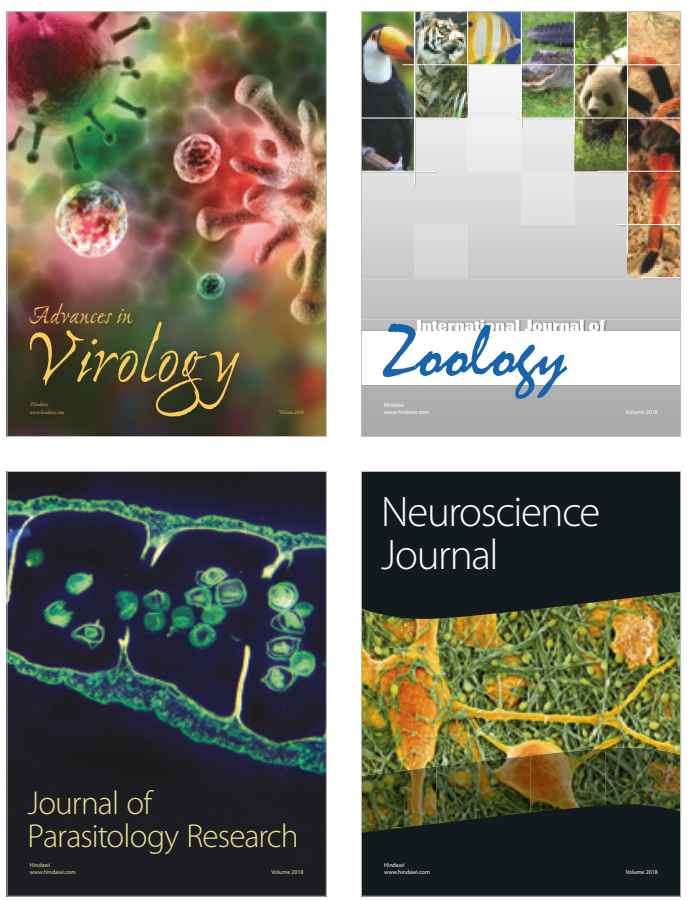
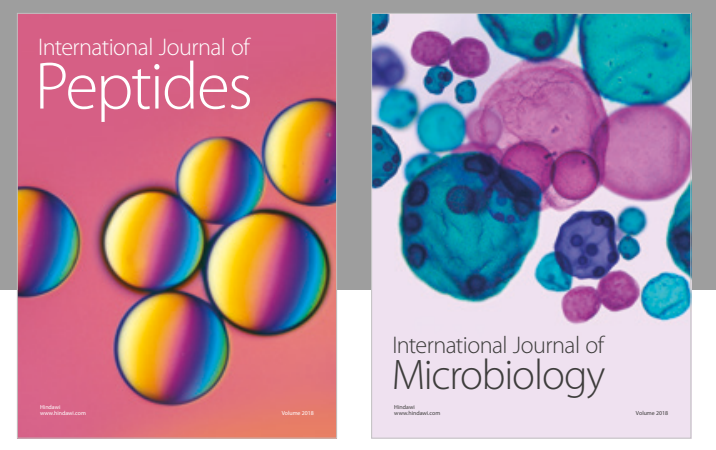

nternational Journal of Microbiology
Journal of
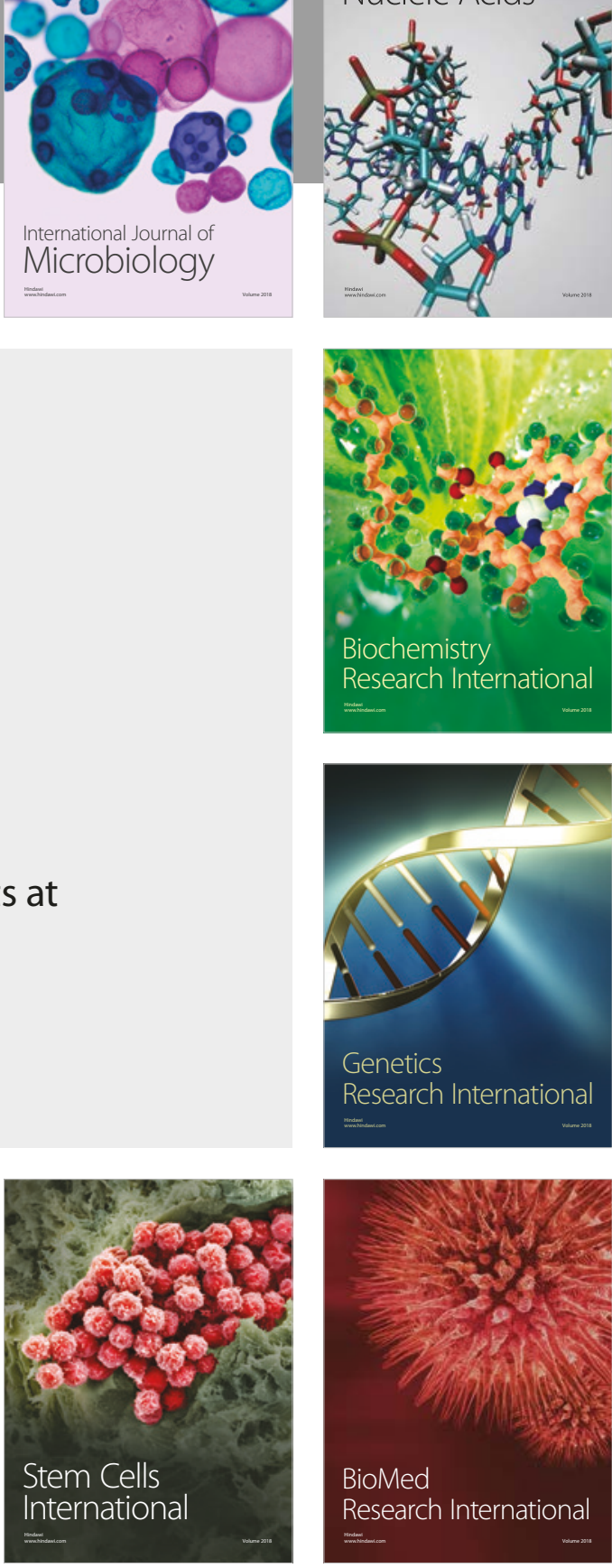
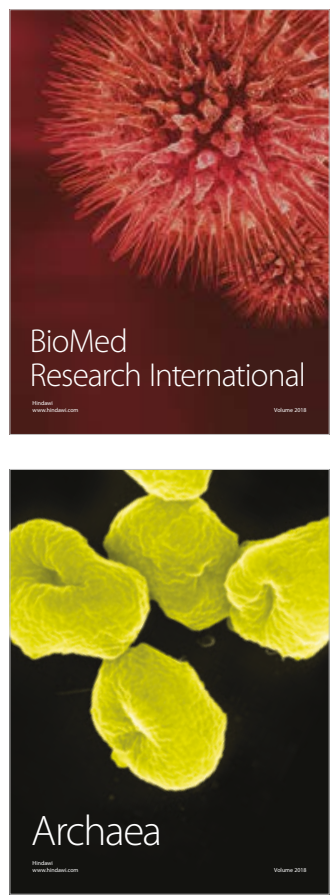